\title{
FOMC Forecasts: Is All the Information in the Central Tendency?
}

\author{
William T. Gavin
}

0

ince 1980, there has been a substantial improvement in the performance of mone-

tary policy among most of the industrialized countries. Bernanke et al. (1998) attribute this success to the adoption of inflation targeting, but they are somewhat vague in defining what it means to have an inflation target. Even countries that do not have numerical inflation targets are said to be inflation targeting if they focus on a long-term objective for price stability (low inflation) and publish inflation forecasts. By this broad definition, even the Federal Reserve may be considered to have an inflation target.

This article describes and documents 23 years of FOMC forecasts. Congress required the Fed to begin preparing and reporting forecasts in 1979.

Section 108 of the Humphrey-Hawkins Act explicitly required the Fed to submit "written reports setting forth (1) a review and analysis of recent developments affecting economic trends in the nation; (2) the objectives and plans... with respect to the monetary and credit aggregates...; and (3) the relationship of the aforesaid objectives and plans to the shortterm goals set forth in the most recent Economic Report of the President." In order to satisfy the third item, the Federal Reserve Chairman began reporting a summary of Fed policymakers' forecasts to Congress in July $1979 .{ }^{1}$ Since then, similar summaries of forecasts have been reported every February and July. Forecasts are made of annual, fourthquarter-over-fourth-quarter growth rates for nominal gross domestic product (GDP), real GDP, and inflation. ${ }^{2}$ Fed policymakers also forecast the average level of unemployment for the fourth quarter of

\footnotetext{
1 The reporting requirements of the Humphrey-Hawkins Act expired in May 2000. Congress amended and continued the reporting requirements in the American Homeownership and Economic Opportunity Act of 2000 (Section 1003).

2 The Fed followed the Bureau of Economic Analysis, switching from GNP to GDP in 1992 .

William T. Gavin is a vice president and economist at the Federal Reserve Bank of St. Louis. Athena Theodorou provided research assistance.

(1) 2003, The Federal Reserve Bank of St. Louis.
}

the year. In February, the forecasts pertain to the current calendar year (referred to below as the 12month-ahead forecasts). In July, forecasts are updated for the current calendar year (6-month-ahead forecasts) and preliminary projections are made for the next calendar year (18-month-ahead forecasts).

Separate forecasts are made by each of the FOMC members (and nonvoting Federal Reserve Bank presidents), but the individual forecasts are not published. ${ }^{3}$ Rather, the Fed reports two summary statistics: the low and the high forecast among all the policymakers and the central tendency, which has been reported since February 1983 and is a smaller range that omits extreme forecasts.

This paper evaluates the information content of the two summary statistics, the full range and central tendency, and defines two FOMC forecasts based on those statistics: the midpoint of the full range (FR) and the midpoint of the central tendency range (CT). The paper compares forecast accuracy, tests for bias and efficiency, and uses encompassing tests to see whether either of these summary statistics encompasses the other. Admittedly, the two forecasts calculated from the FR and CT are quite close. In many of the tests, we cannot distinguish between the two. However, where statistically significant differences exist, they generally favor the use of the FR.

\section{THE HISTORICAL RECORD}

If the outlying forecasts for the FR and $\mathrm{CT}$ are symmetric, then the two will be the same. The FOMC has generated a large number of forecasts since 1979. There are two alternative ranges for each of four forecasted economic variables made at three different horizons (24 separate forecast series rang-

\footnotetext{
3 The FOMC is the policymaking committee of the Federal Reserve System. When the Board is full, the Committee consists of the 7 governors of the Board, the president of the Federal Reserve Bank of New York, and 4 of the remaining 11 Federal Reserve Bank presidents who serve on a rotating basis. All 12 presidents attend every meeting, contribute to the discussion, and provide forecasts that are summarized in testimony to the Congress. In this article, when we refer to the FOMC forecasts we mean the summary of forecasts that are collected from FOMC members and nonvoting Federal Reserve Bank presidents.
} 
ing from 18 to 23 years each). To compare the forecast with the outcome, we measure actual output, inflation, and unemployment using real-time data rather than the latest vintage data.

There is always an issue about how to define the "actual" data because the data are regularly revised as we get more information about the past. The analysis in this paper is based on the real-time data that are maintained at the Federal Reserve Bank of Philadelphia. They created vintages of data that were available in the middle of the following months: February, May, August, and November. ${ }^{4}$ Except where explicitly noted, the actual values are taken from the first report for a calendar year that occurs at the end of January and is stored in the "February" files by the Philadelphia Fed.

In preliminary work we examined the rootmean-squared errors (RMSE) calculated using the different versions of the data that became available during the year following the forecast period. We found that the FOMC's nominal GDP and real GDP forecasts were most accurate for the first released figures reported in February. The FR forecast for inflation was about equally accurate using the February or November data, and the CT inflation forecast was most accurate using the November data. In all cases the inflation forecasts were closer to the February version than they were to the May version. The unemployment data were rarely revised within the first year, and there were no revisions to the fourth-quarter average in our sample.

The 12-month forecasts are used to illustrate the FOMC forecasts in Figure 1. The top panel of Figure 1 shows nominal GDP growth. Through 1995, the FOMC, on average, overpredicted nominal GDP growth. The nominal GDP forecast errors were particularly large in years that included recessions: 1981-82, 1990-91, and 2001. On average the real GDP forecasts shown in the second panel appear to be unbiased, but the forecast errors were large and negative in recessions and large and positive in the years 1995 through 1999. There was an unexpected increase in productivity growth during the latter half of the 1990s.

The third panel shows the inflation forecasts made by the FOMC. The FOMC began forecasting the implicit price deflator for GNP in 1979. Much of the bias in the nominal GDP forecast came from a tendency to overpredict inflation in the 1980s.

\footnotetext{
4 The forecasts and real-time data used in this article are available on
} the Bank's web site: < research.stlouisfed.org >
The FOMC continued reporting forecasts for the deflator until 1989, when it began making inflation forecasts in terms of the consumer price index (CPI). CPI inflation accelerated to 7 percent in the second two quarters of 1990, exceeding the FOMC forecasts. Inflation decelerated rapidly in 1991 and stayed, on average, below the forecast through the 1990s. In 2000, the FOMC switched once again, this time to the chain price index for personal consumption expenditures (PCE).

The fourth-quarter average unemployment rate is shown in the bottom panel of Figure 1. Here, the interesting features are the trend decline of unemployment that appears to mirror the decline of inflation, the tendency to overpredict unemployment in the 1990s (another facet of the surprisingly high productivity growth), and the relatively accurate prediction of unemployment in the 1990-91 recession.

Descriptive statistics and tests comparing the alternative forecasts are shown in Table 1. Our analysis uses 1983-2001 data for the 6- and 12-month forecasts and 1984-2001 data for the 18-month forecasts so that we can compare the forecasts derived from the FR with those computed from the CT. ${ }^{5}$

Five statistics are reported in Table 1: the mean error, the RMSE, p-values from a Wilcoxon signed-rank statistic that tests whether the RMSEs from the FR and $\mathrm{CT}$ forecasts are equal, the widths of the intervals for FR and CT, and the percentage of times that the actual value fell outside the FR and CT.

As we saw with the 12-month forecasts in Figure 1, the FOMC tended to overpredict inflation, nominal GDP growth, and the unemployment rate. In each of these cases, the negative bias in the mean error was largest for the 18-month forecasts. There was no bias in the 6-month real GDP forecast and a positive bias in the 12- and 18-month real GDP forecasts.

The RMSEs are shown in the second row of each panel. The nominal GDP RMSEs were largest, 10 to 20 percent larger than those for real GDP and almost twice as large as those for inflation. Generally, the real GDP growth and inflation errors were weakly negatively correlated. The probability values of a Wilcoxon signed-rank test are reported in parentheses in the third row of each panel for the FR forecasts. This is a test of the null hypothesis that

\footnotetext{
5 See Gavin and Mandal (2002) for an analysis of the FR forecasts for output and inflation, including a comparison with the Blue Chip consensus and Green Book forecasts. They find that the FOMC's output forecasts were as good as the Blue Chip and Green Book forecasts The FOMC's inflation forecasts were better than the Blue Chip, but not as good as the Green Book.
} 


\section{Figure 1}

FOMC Forecasts: 1979 to 2001
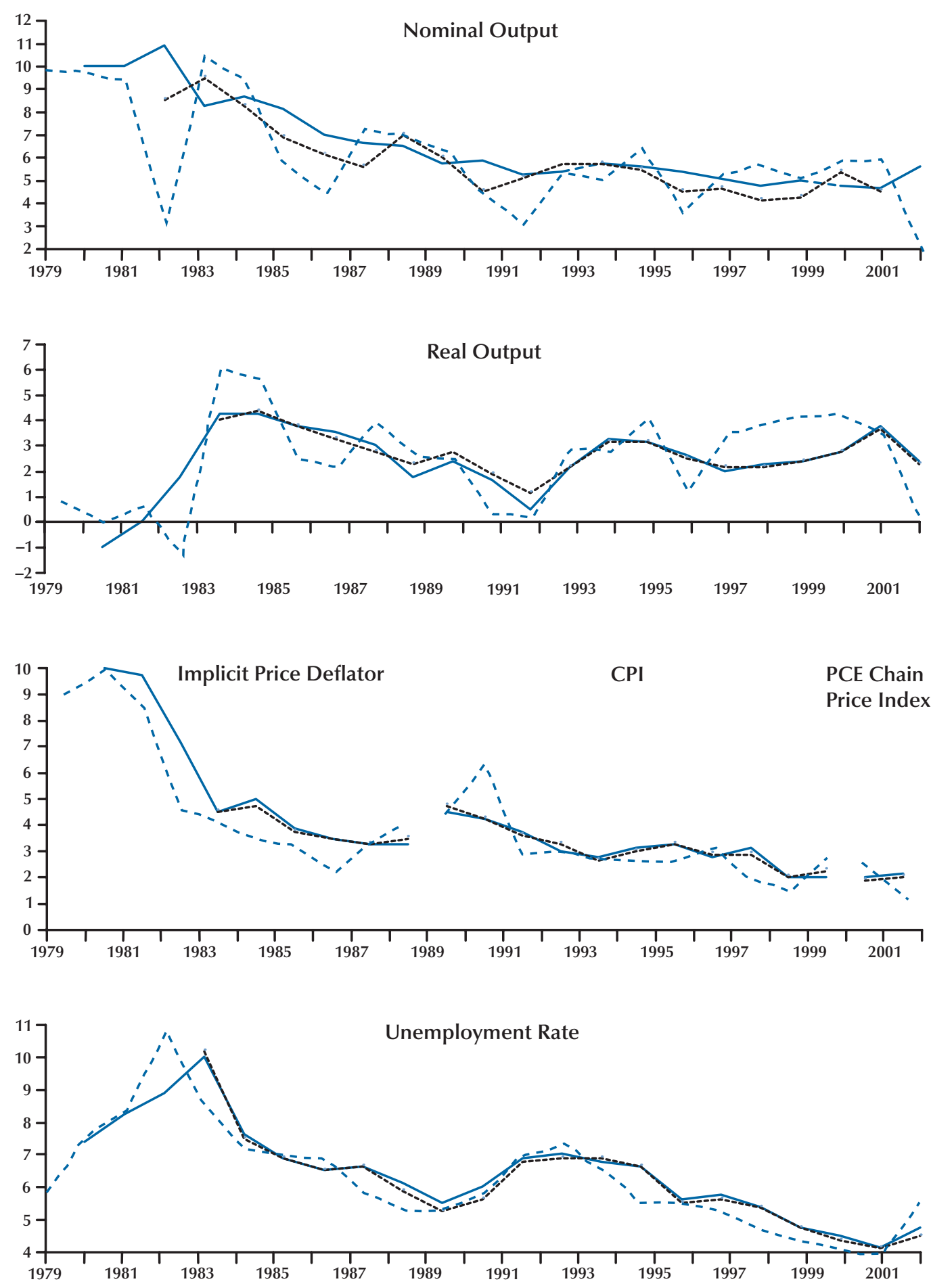

NOTE: Actual values (blue dashed lines) are those first available in February of the following year. The FR is shown by a solid line and the CT by the black dotted line. 


\section{Table 1}

\section{FOMC Forecasts by Forecast Horizon}

\begin{tabular}{|c|c|c|c|c|c|c|}
\hline & \multicolumn{3}{|c|}{ FR } & \multicolumn{3}{|c|}{ CT } \\
\hline & 6-month & 12-month & 18-month & 6-month & 12-month & 18-month \\
\hline \multicolumn{7}{|l|}{ Nominal GDP } \\
\hline Mean error & -0.31 & -0.17 & -0.43 & -0.35 & -0.18 & -0.59 \\
\hline RMSE & 0.97 & 1.34 & 1.52 & 0.93 & 1.45 & 1.67 \\
\hline Wilcoxon signed-rank test ( $p$-value) & $(0.98)$ & $(0.14)$ & $(0.05)$ & & & \\
\hline Width of range in percentage points & 1.61 & 2.09 & 2.37 & 0.66 & 0.72 & 0.98 \\
\hline Percent of time outside the range & 53 & 58 & 44 & 79 & 89 & 72 \\
\hline \multicolumn{7}{|l|}{ Real GDP } \\
\hline Mean error & -0.01 & 0.25 & 0.19 & 0.00 & 0.20 & 0.09 \\
\hline RMSE & 0.78 & 1.26 & 1.33 & 0.79 & 1.27 & 1.41 \\
\hline Wilcoxon signed-rank test ( $p$-value) & $(0.86)$ & $(0.86)$ & $(0.56)$ & & & \\
\hline Width of range in percentage points & 1.11 & 1.43 & 1.55 & 0.42 & 0.53 & 0.51 \\
\hline Percent of time outside the range & 68 & 68 & 50 & 95 & 100 & 78 \\
\hline \multicolumn{7}{|l|}{ Inflation } \\
\hline Mean error & -0.29 & -0.41 & -0.60 & -0.34 & -0.39 & -0.65 \\
\hline RMSE & 0.51 & 0.69 & 0.85 & 0.52 & 0.69 & 1.01 \\
\hline Wilcoxon signed-rank test ( $p$-value) & $(0.42)$ & $(0.92)$ & $(0.07)$ & & & \\
\hline Width of range in percentage points & 0.95 & 1.32 & 1.94 & 0.39 & 0.49 & 0.63 \\
\hline Percent of time outside the range & 47 & 53 & 39 & 89 & 74 & 67 \\
\hline \multicolumn{7}{|l|}{ Unemployment } \\
\hline Mean error & -0.15 & -0.29 & -0.31 & -0.12 & -0.20 & -0.23 \\
\hline RMSE & 0.38 & 0.60 & 0.81 & 0.37 & 0.63 & 0.80 \\
\hline Wilcoxon signed-rank test ( $p$-value) & $(0.70)$ & $(0.73)$ & $(0.76)$ & & & \\
\hline Width of range in percentage points & 0.56 & 0.64 & 0.88 & 0.19 & 0.22 & 0.35 \\
\hline Percent of time outside the range & 37 & 68 & 67 & 68 & 89 & 78 \\
\hline
\end{tabular}

NOTE: Wilcoxon's signed-rank test is used to test the null hypothesis that the forecasts are equally accurate (that is, the RMSEs are equal). The significance levels were computed from a program provided by Rob van Son found at $<$ http://www.fon.hum.uva.nl/Service/Statistics/Signed_Rank_Algorihms.html>.

Bold cells indicate that the probability value is less than 10 percent.

The data span the period 1983-2001 for 6- and 12-month horizons and 1984-2001 for the 18-month horizon.

the RMSEs from the FR and CT forecasts are equal. We use a Wilcoxon signed-rank statistic because Diebold and Mariano (1995) show that this test statistic is well-sized in cases where the sample is small and the alternative forecast errors are highly correlated and possibly serially correlated-as we expect for the 18-month forecasts. ${ }^{6}$ In only 2 of the 24 cases is the probability value less than 10 percent - the 18-month forecasts for nominal GDP growth and inflation. In both cases the forecast derived from the FR was more accurate than the forecast derived from the CT.

The fourth row of each panel reports the average

6 The 18-month forecast for year $t$ is made before the actual value for year $t-1$ is known. Any surprise in the actual value for year $t-1$ will be part of the forecast error for year $t-1$. This surprise is also likely to be reflected in the actual value (and forecast error) for year $t$. Thus, we can expect first-order serial correlation in the 18-month forecast errors. 
width of the FR or CT intervals. The width of the range is the distance in percentage points between the high- and low-point forecasts. We define the FOMC consensus forecast as the midpoint of the range between the high and low forecasts. A way to gauge whether the range is a good measure of the uncertainty about the forecast is to see how often the actual value falls outside the range. The bottom row in each panel reports the percentage of time that the outcome fell outside the reported FR or CT. The actual values were outside the CT most of the time, indeed, all of the time for the 12-month output forecasts.

The average width of the FR for the 18-month output forecasts is 1.55 percentage points. The actual value fell outside this range 50 percent of the time. The range of 12-month output forecasts was almost as wide (1.43 percentage points), but the actual value fell outside this range 68 percent of the time. At the shortest horizon, the width of the range fell to 1.11 percentage points, and the actual value also fell outside this range 68 percent of the time.

The economic future is always uncertain, and a wider forecast range reflects greater disagreement among the policymakers about economic trends and policy objectives. However, even if the forecasts of all the policymakers were identical (perfect consensus), they would likely be wrong because the future is inherently unpredictable. Table 2 attempts to gauge the degree of consensus about the outlook, relative to the economy's unpredictability. The table shows the ratios of the RMSEs of the consensus forecasts to one-half the width of the forecast ranges. (We use one-half the range to make the scale comparable to the RMSE, which is an index of unpredictability.) The width of the range is an inverse measure of consensus. As such, the ratios reveal, in a simple way, the degree of consensus among the policymakers about the outlook for a variable, relative to the difficulty of predicting that variable. A high ratio, for example, indicates a strong consensus regarding the outlook, relative to the unpredictability of the variable.

In every case except for the 18-month inflation forecasts, the RMSE is larger than half the width of the range. Paradoxically, the highest figures (where the consensus is strong relative to the degree of predictability) are for "real" variables, such as GDP and the unemployment rate, over which the Fed has little control. At the same time, the smallest figures are observed for inflation, over which the Fed is widely regarded as having considerable influence,
Table 2

\section{A Relative Measure of FOMC Consensus}

\begin{tabular}{lccc} 
& \multicolumn{3}{c}{ Forecast horizon } \\
\cline { 2 - 4 } & 6-month & 12-month & 18-month \\
\hline Nominal GDP & 1.21 & 1.28 & 1.28 \\
Real GDP & 1.40 & 1.76 & 1.72 \\
Inflation & 1.08 & 1.05 & 0.87 \\
Unemployment & 1.35 & 1.86 & 1.83
\end{tabular}

NOTE: The values in this table are calculated as the ratio of the RMSE to one-half the width of the range as reported in Table 1. It is a measure of the predictive uncertainty (RMSE) divided by an inverse measure of policy consensus. Therefore, a high number indicates a relatively high degree of consensus.

although perhaps not over horizons as short as 18 months. The individual inflation forecasts reflect, to a greater or lesser extent, the policymaker's beliefs about the desired long-run inflation objective. Among inflation forecast horizons, the least consensus emerges for the longest horizon - 18 months-where the Fed's control presumably is the strongest. Since the formation of the European Central Bank, the United States and Japan are the only major central banks in the world that do not announce a numerical objective for inflation. The statistics in Table 2 suggest one reason why U.S. policymakers may have been reluctant to adopt a specific objective for inflation-namely, there is little consensus about what the numerical objective should be.

\section{ARE THE FOMC FORECASTS UNBIASED?}

There is a problem in evaluating the FOMC inflation forecasts because, as noted above, the FOMC switched among price indices over our sample period. Our analysis in Figure 1 and Tables 1, 2, and A1 used the inflation forecasts for the different price indices as they were reported. In the remaining part of the paper, we use an implied forecast that is calculated by subtracting the midpoint of the range of real GDP forecasts from the midpoint of the range of nominal GDP forecasts (Tables 3 through 5). We do this because the FOMC has consistently forecasted nominal and real output since 1979. Even when the Fed was basing the inflation forecast on the CPI (from 1989 through 1999), they were also reporting forecasts for both nominal and real output, so there was always an implied forecast for the output deflator. 
In this section, we check the alternative forecasts for unbiasedness and estimate the following regression in the first part of our test:

$$
x_{t}=\alpha+\beta_{t-i} x_{t}^{f}+{ }_{t-i} \varepsilon_{t},
$$

where $x$ is the variable being forecast (the fourthquarter-over-fourth-quarter growth rate of output or the price deflator for output). The forecast $\left(x^{f}\right)$ is indexed according to the time when the forecast was made ( $t-i$, where $i$ refers to three forecast horizons) and the year to which it applies $(t)$. If the estimates of $(\alpha, \beta)$ are equal to $(0,1)$, the forecasts are unbiased. We use an F-statistic to test for unbiasedness. Holden and Peel (1990) show that even if we can reject the null hypothesis that $(\alpha, \beta)$ is equal to $(0,1)$, it is still possible that the forecasts may be unbiased. The intuition for their result can be understood by thinking about equation (1) as a mechanism for combining unbiased forecasts where the constant is an unbiased forecast of the series. If we cannot reject the null hypothesis, we can conclude that the forecast is unbiased. If we reject the null hypothesis, it is necessary to examine the properties of the forecast error, $x_{t}-{ }_{t-i} x_{t}^{f}$. To make a complete test of unbiasedness, we also compute the regression

$$
x_{t}-{ }_{t-i} x_{t}^{f}=\gamma+{ }_{t-i} \varepsilon_{t}^{\gamma}
$$

and test whether $\gamma$ is equal to zero. In addition, we must take account of possible serial correlation in the error for the July next-year forecast. Because the forecast horizon is longer than the interval over which output growth is measured, the forecast error for year $t$ is not available when the forecasts for year $t+1$ are made. Therefore, information that arrives in the second half of year $t$ may be reflected in forecast errors for both years $t$ and $t+1$. If it does, the errors will display first-order serial correlation. For this case, Hansen (1982) has shown that ordinary least-squares (OLS) estimates will be unbiased, but the standard errors will be too small, leading to too many rejections of the null hypothesis. Therefore we use the correction for serial correlation suggested by Hansen (1982) when we report test statistics for the July next-year forecasts.

OLS estimates of equations (1) and (2) for the FOMC forecasts are listed in Table 3, which includes the estimates of $\alpha$ and $\beta$, with standard errors in parentheses. The third column of results shows the probability values of the F-statistic for the null joint hypothesis that $(\alpha, \beta)=(0,1)$. For the 12 cases with nominal and real output, the probability values are all above 10 percent, so we conclude that the output forecasts are unbiased. Table 2 also reports the t-statistics for estimates of $\gamma$ in equation (2). It is not necessary to estimate equation (2) in the case of the output forecasts, however, because we could not reject unbiasedness using the F-statistic.

In contrast, the probability values of the Fstatistic for the inflation and unemployment forecasts are quite low. In the case of inflation, the F-statistic always rejects unbiasedness at a 10 percent level. The fifth column of Table 3 reports the probability values for the t-statistic for testing whether $\gamma$ is equal to zero. Here we find strong evidence that the inflation forecasts are biased, which is not too surprising since the inflation forecasts were above actual inflation most of the time (see Figure 1). In the case of the unemployment rate, we could reject the joint hypothesis that $(\alpha, \beta)=(0,1)$ in five of the six cases. In two of those, however, we could not reject that the mean of the forecast error was zero. Here, the FR forecasts for unemployment were found to be significantly biased, but the CT forecasts were not.

\section{ARE THE FOMC FORECASTS EFFICIENT?}

Forecasts are considered efficient if the forecaster takes account of all relevant information. This means that forecasters continue to invest in using more information as long as benefits of using more information exceed the costs of acquiring it. In practice, we check for informational efficiency by testing whether the forecast errors are systematically related to information that was readily available when the forecasts were made. Because the data set is small, we check for a bivariate relationship between the forecast errors and information from the past. To conduct this test for efficiency, we run the following regression:

$$
{ }_{t-i} e_{t}=\alpha+\beta_{t-i} x_{t-j}^{k}+{ }_{t-i} u_{t},
$$

where ${ }_{t-i} e_{t}$ is the forecast error for year $t$ (for each of the four variables) made at the $t-i$ horizon. So there will be a total of 24 different dependent variables: The FR and the CT each have three horizons for each of the four forecasted variables. The term ${ }_{t-i} x_{t-j}^{k}$ is the $t-j$ information variable that was available when the forecast was made. Thus, $j=2$ when the dependent variable is an 18 -month forecast error, and $j=1$ when it is a 6 - or 12 -month forecast error. The superscript $k$ refers to the information variable included in our efficiency test.

In principle, we could test efficiency against 


\section{Table 3}

\section{Tests for Unbiasedness}

\begin{tabular}{|c|c|c|c|c|c|}
\hline \multicolumn{6}{|c|}{$\begin{array}{l}x_{t}^{f}+{ }_{t-i} \varepsilon_{t}^{a} \\
\gamma+{ }_{t-i} \varepsilon_{t}^{b}\end{array}$} \\
\hline & Forecast & $\alpha$ (SE) & $\beta$ (SE) & F-statistic (p-value) & $\gamma(\mathbf{p}$-value $)$ \\
\hline \multirow[t]{6}{*}{ Nominal GDP } & 6-month FR & $-0.477(0.86)$ & $1.028(0.14)$ & 0.396 & 0.172 \\
\hline & 6-month CT & $-0.560(0.80)$ & $1.035(0.13)$ & 0.268 & 0.104 \\
\hline & 12-month FR & $0.269(1.32)$ & $0.925(0.22)$ & 0.823 & 0.596 \\
\hline & 12-month CT & $0.674(1.41)$ & $0.855(0.23)$ & 0.720 & 0.599 \\
\hline & 18-month FR & $1.444(1.94)$ & $0.681(0.33)$ & 0.326 & 0.245 \\
\hline & 18-month CT & $2.182(1.72)$ & $0.541(0.28)$ & 0.101 & 0.141 \\
\hline \multirow[t]{6}{*}{ Real GDP } & 6-month FR & $-0.301(0.47)$ & $1.098(0.15)$ & 0.799 & 0.960 \\
\hline & 6-month CT & $-0.312(0.48)$ & $1.105(0.15)$ & 0.781 & 1.000 \\
\hline & 12-month FR & $-0.068(0.92)$ & $1.115(0.32)$ & 0.677 & 0.412 \\
\hline & 12-month CT & $-0.697(1.08)$ & $1.330(0.38)$ & 0.542 & 0.484 \\
\hline & 18-month FR & $-0.124(1.49)$ & $1.121(0.56)$ & 0.829 & 0.560 \\
\hline & 18-month CT & $0.644(1.67)$ & $0.794(0.61)$ & 0.915 & 0.800 \\
\hline \multirow[t]{6}{*}{ Inflation } & 6-month FR & $-0.075(0.35)$ & $0.926(0.11)$ & 0.028 & 0.009 \\
\hline & 6-month CT & $-0.198(0.35)$ & $0.952(0.11)$ & 0.009 & 0.002 \\
\hline & 12-month FR & $0.233(0.41)$ & $0.790(0.13)$ & 0.006 & 0.005 \\
\hline & 12-month CT & $0.256(0.43)$ & $0.788(0.13)$ & 0.012 & 0.009 \\
\hline & 18-month FR & $0.115(0.54)$ & $0.775(0.16)$ & 0.002 & 0.001 \\
\hline & 18-month CT & $0.592(0.59)$ & $0.615(0.17)$ & 0.001 & 0.003 \\
\hline \multirow[t]{6}{*}{ Unemployment } & 6-month FR & $0.395(0.40)$ & $0.909(0.06)$ & 0.080 & 0.072 \\
\hline & 6-month CT & $0.671(0.35)$ & $0.868(0.06)$ & 0.036 & 0.152 \\
\hline & 12-month FR & $0.798(0.56)$ & $0.824(0.09)$ & 0.019 & 0.033 \\
\hline & 12-month CT & $1.144(0.57)$ & $0.779(0.09)$ & 0.032 & 0.160 \\
\hline & 18-month FR & $1.425(0.96)$ & $0.713(0.16)$ & 0.058 & 0.099 \\
\hline & 18-month CT & $1.480(1.01)$ & $0.713(0.17)$ & 0.122 & 0.218 \\
\hline
\end{tabular}

NOTE: FR represents the forecasts calculated as the midpoint of the full range and CT represents the forecasts calculated as the midpoint of the CT. The tests use the sample period for which the CT is available: 1983-2001 for 6- and 12-month forecasts and 1984-2001 for 18-month forecasts. Bold cells indicate that the probability value is less than $\mathbf{1 0}$ percent.

any information that was available at the time the forecasts were made. In Table 4A, we include the most recently available information on the variables being forecasted - nominal GDP growth, real GDP growth, inflation, and the unemployment rate. The table includes the $\mathrm{p}$-values for the $\mathrm{t}$-statistic testing the null hypothesis that $\beta=0$. We also derive $\mathrm{Q}-$ statistics (from the regression of the forecast error on the last observed value of the forecasted variable) to test for serial correlation in the forecast errors. For example, in Table 4A, the first row of results are calculated using the 18-month nominal GDP forecast error. The Q-statistic is taken from the equation that includes past nominal GDP growth on the righthand side. In the second row of each panel, the forecast error for real GDP growth is the dependent variable and the Q-statistic is taken from the equation that includes past GDP growth as the information variable.

The top panel of Table 4A includes tests using the 18-month forecasts. The July next-year forecast is made before the current-year results are known, 


\section{Table 4A}

\section{Are the FOMC Forecasts Efficient? History of Forecast Variables}

(Using May vintage for July forecasts, values in the table are probability values for the t-statistic on the coefficient $\beta$ in equation (3): ${ }_{t-i} e_{t}=\alpha+\beta_{t-i} x_{t-j}^{k}+{ }_{t-i} u_{t}$.)

\begin{tabular}{lccccc} 
& Nominal GDP & Real GDP & Inflation & Unemployment rate & $\mathbf{Q}^{*}$ \\
\hline $\begin{array}{l}\text { 6-month forecast errors } \\
\text { FR }\end{array}$ & & & & & \\
$\quad$ Nominal GDP & 0.25 & 0.64 & 0.23 & 0.67 & $\mathbf{0 . 0 0}$ \\
$\quad$ Real GDP & 0.10 & 0.30 & 0.28 & 0.49 & $\mathbf{0 . 0 1}$ \\
Inflation & 0.58 & 0.38 & 0.58 & 0.70 & 0.11 \\
$\quad$ Unemployment rate & 0.22 & 0.20 & 0.93 & 0.08 & $\mathbf{0 . 0 4}$ \\
CT & & & & & \\
Nominal GDP & 0.14 & 0.56 & 0.11 & 0.64 & $\mathbf{0 . 0 0}$ \\
Real GDP & $\mathbf{0 . 0 3}$ & 0.21 & 0.15 & 0.41 & $\mathbf{0 . 0 3}$ \\
Inflation & 0.34 & 0.22 & 0.66 & 0.55 & 0.16 \\
Unemployment rate & 0.12 & $\mathbf{0 . 0 8}$ & 0.75 & $\mathbf{0 . 0 1}$ & 0.39
\end{tabular}

12-month forecast errors

FR

Nominal GDP
Real GDP
Inflation
Unemployment rate
CT

$0.21 \quad 0.58$

$0.58 \quad 0.25$

0.70

0.03

0.27

0.46

0.57

0.28

0.06

0.67

0.14

0.11

0.52

0.48

0.12

0.05

Nominal GDP

0.10

0.38

0.90

0.05

Real GDP

0.21

0.48

0.23

0.60

0.01

Inflation

0.24

0.57

0.37

0.09

Unemployment rate

0.42

0.32

0.01

0.44

0.94

0.15

0.22

\section{8-month forecast errors}

FR

Nominal GDP
Real GDP
Inflation
Unemployment rate
CT

0.01

$0.08 \quad 0.17$

0.30

0.82

0.38

0.08

0.51

0.34

0.23

0.10

0.28

0.34

0.11

0.16

0.17

0.23

0.73

0.01

Nominal GDP
Real GDP
Inflation
Unemployment rate

$\begin{array}{ll}\mathbf{0 . 0 2} & 0.17 \\ 0.10 & 0.22 \\ 0.11 & 0.62 \\ 0.19 & 0.31\end{array}$

$\mathbf{0 . 1 0}$
0.48
$\mathbf{0 . 0 5}$
0.60

0.86

0.47

0.17

0.46

0.18

0.62

0.07

0.04

0.31

0.05

0.01

${ }^{*} \mathrm{Q}$ is a test for randomness based on the first four autocorrelations of the residual in the regression with the lag of the forecast variable. For example, in the first row of each panel we use the residuals from the equation including lagged nominal GDP growth. Bold cells indicate that the probability value is less than 10 percent. 


\section{Table 4B}

\section{Are the FOMC Forecasts Efficient? Interest Rates and Money}

(Using June interest rates for July forecasts and January rates for February forecasts, values in the table are probability values for the t-statistic on the coefficient $\beta$ in equation (3): ${ }_{t-i} e_{t}=\alpha+\beta_{t-i} x_{t-j}^{k}+{ }_{t-i} u_{t}$.)

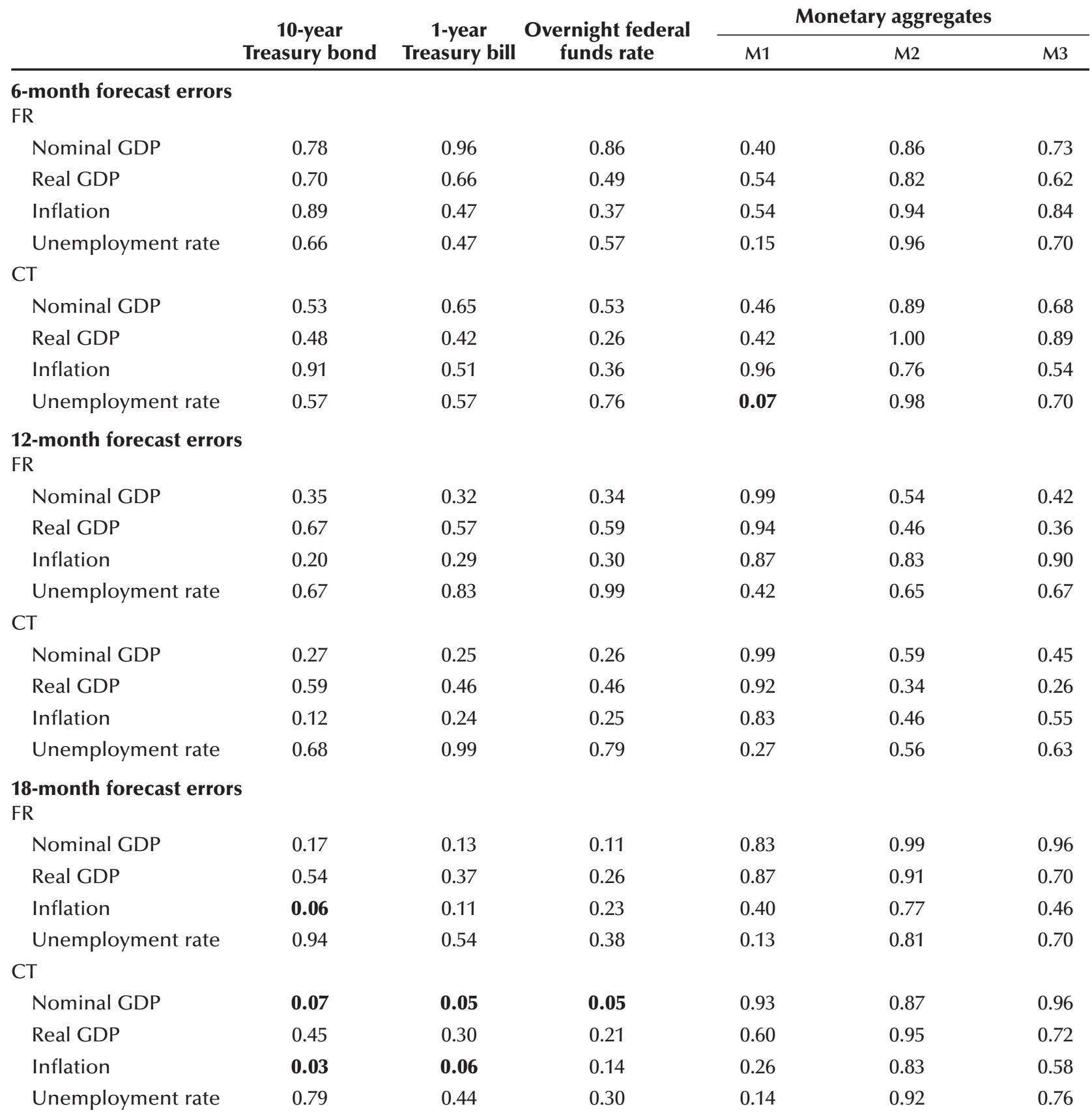

${ }^{*} \mathrm{Q}$ is a test for randomness based on the first four autocorrelations of the residual in the regression with the lag of the forecast variable. For example, in the first row we use the residuals from the equation including lagged nominal GDP growth. Bold cells indicate that the probability value is less than 10 percent. 
so in this case we use the results from the previous year. We are testing whether the 18-month forecast errors from year $t$ are related to the variables dated $t-2$. We report results using both the FR and the CT forecasts. In the case of the FR, coefficients on nominal GDP growth, real GDP growth, and inflation are statistically significant at a 10 percent critical level. In the case of the CT forecasts, the nominal GDP forecast errors are related to past nominal GDP growth and past inflation. Inflation forecast errors are related to past inflation and to the past unemployment rate.

The 12-month forecasts are shown in the middle panel. There is only one significant coefficient among the 24 coefficients reported. The CT forecast for nominal GDP growth is correlated with last year's nominal GDP growth. However, six of the eight Qstatistics have probability values less than 10 percent. In the case of the 6-month forecasts, none of the FR forecasts were related to past values of the information variables, but both the nominal and real GDP forecasts errors were serially correlated.

Since the FOMC was also setting targets for monetary growth and the federal funds rate for much of this period, the forecasts were checked for efficiency with respect to information about monetary growth and interest rates. The FOMC set targets for M1, M2, and M3; all were included. Also included were the currently observed interest rates for the overnight federal funds rate, 1-year Treasury bills, and 10-year Treasury bonds. Although the FOMC does not set targets for Treasury rates, they embody expectations about future inflation and future overnight interest rates.

The results including money and interest rates are shown in Table 4B. The monetary data were those reported to the FOMC at the first policy meeting of the year. They are fourth-quarter-over-fourthquarter growth rates. The interest rates are averages for the months of January (used with the February forecasts) and June (used with the July forecasts). Again, there is almost no evidence that this information was ignored. An exception may be the 18-month CT forecasts for nominal GDP and inflation. Here, the forecast errors for nominal GDP growth and inflation are significantly related to interest rates. Only in one case, the 6-month forecast error for the unemployment rate, was past money growth significant.

With some exceptions, the forecast errors appear to be serially correlated, but unrelated to our information variables. When the forecasts fail tests for efficiency, it is usually a forecast calculated from the CT rather than the FR. We estimated 240 coefficients on past information. We found that 19 of these were significant at a 10 percent level; of those 19, only 4 applied to cases using an FR forecast. Overall, there were fewer significant coefficients than one would expect to observe by chance, even if the forecasts were fully efficient.

\section{DO EITHER THE RANGE OR CENTRAL TENDENCY FORECASTS ENCOMPASS THE OTHER?}

In this section, we test whether the CT or the FR encompasses the other. We say that one forecast encompasses another if the former incorporates all of the relevant information of the latter. If it does, then adding information from the latter will not help predict the actual value. We run the following regression:

$$
x_{t}-{ }_{t-i} x_{t}^{f r}=c+\beta_{c t-i} x_{t}^{c t}+{ }_{t-i} \varepsilon_{t}^{f r},
$$

where we compare the FR and CT forecasts of $x$, $x^{f r}$, and $x^{c t}$. Forecast $x^{f r}$ encompasses $x^{c t}$ if $\beta_{c t}=0$. We test the alternative, that is, forecast $x^{c t}$ encompasses $x^{f r}$, by switching the roles of the FR and CT forecasts. The results of the encompassing tests are shown in Table 5. The results are $\mathrm{p}$-values for the $t$-statistic testing that the coefficient $\beta$ is equal to zero. In all cases except the unemployment forecasts, the probability values are greater than 10 percent and we cannot reject that they both encompass the other. In practical terms, this means that if you have one forecast, you do not need the other. In the case of the unemployment rate, we can reject that the 18- and 12-month FR forecasts encompass the CT tendency forecasts, and that the 12- and 6-month CT forecasts encompass the respective FR forecasts. In practical terms, this means that there is useful and independent information in both forecasts.

\section{CONCLUSIONS}

This article reviews two decades of experience with FOMC forecasts. As one would expect, forecasts calculated from the FR are very similar to those calculated from the CT. In the two cases where there is a significant difference, the forecasts constructed from the FR were more accurate than those calculated from the CT. In two cases where the FOMC was forecasting the next calendar year in July, we found that the nominal GDP and inflation forecasts that 


\section{Table 5}

\section{Encompassing Tests for the FOMC Forecasts: FR and CT}

(Probability values for the t-statistic on $\beta$ in equations (4): $x_{t}-{ }_{t-i} x_{t}^{f r}=c+\beta_{c t} t_{-i} x_{t}^{c t}+{ }_{t-i} \varepsilon_{t}^{f r}$ and $x_{t}-{ }_{t-i} x_{t}^{c t}=c+\beta_{f r t-i} x_{t}^{f r}+{ }_{t-i} \varepsilon_{t}^{c t}$.)

\begin{tabular}{|c|c|c|c|c|}
\hline \multirow[b]{2}{*}{ Forecast horizon } & \multicolumn{2}{|c|}{ Nominal GDP forecasts } & \multicolumn{2}{|c|}{ Real GDP forecasts } \\
\hline & FR encompasses CT & CT encompasses FR & FR encompasses CT & CT encompasses FR \\
\hline 6-month & 0.68 & 0.84 & 0.45 & 0.41 \\
\hline 12-month & 0.57 & 0.80 & 0.64 & 0.37 \\
\hline 18-month & 0.31 & 0.17 & 0.83 & 0.69 \\
\hline
\end{tabular}

\begin{tabular}{lccccr} 
& \multicolumn{2}{c}{ Inflation forecasts } & & \multicolumn{2}{c}{ Unemployment forecasts } \\
\cline { 2 - 3 } & FR encompasses CT & CT encompasses FR & & FR encompasses CT & CT encompasses FR \\
\hline 6-month & 0.73 & 0.78 & 0.23 & $\mathbf{0 . 0 3}$ \\
12-month & 0.18 & 0.28 & $\mathbf{0 . 0 5}$ & $\mathbf{0 . 0 4}$ \\
18-month & 0.11 & 0.26 & $\mathbf{0 . 0 7}$ & 0.14
\end{tabular}

NOTE: Bold cells indicate the null hypothesis (that the FR encompasses the CT or vice versa) is rejected with a 10 percent critical region.

included the outliers were significantly more accurate than those taken from the $\mathrm{CT}$. We also found that the sizes of the ranges reported were not very closely related to the inherent unpredictability in a variable. Nominal and real output growth rates were more variable and less predictable than inflation, but the range for the high and low 18-month inflation forecasts were larger than those for the output measures. One inference is that there was a wide difference of opinion among FOMC members regarding the medium-term outlook for inflation, relative to the underlying predictability of inflation. This may explain, in part, the FOMC's reluctance to publicly commit to an inflation target.

We could not reject the hypothesis that the FOMC forecast was unbiased in any case involving nominal or real output growth. In contrast, all six forecasts of inflation were significantly biased. In the case of the unemployment rate, we could reject unbiasedness for all of the forecasts calculated from the FR, but for none calculated from the CT.

In general, the FOMC passed tests for efficiency when the tests involved past values of nominal and real output growth, inflation, the unemployment rate, interest rates, and monetary growth. To the extent that the CT and the FR were different, the CT failed the tests more often, especially in the cases using the 18-month forecasts. The encompassing tests did not distinguish between the $\mathrm{CT}$ and the FR forecasts.

Overall, the FR forecasts produced smaller RMSEs and were more efficient than the CT forecasts. For the purposes of doing research using the FOMC's GDP growth and inflation forecasts, the FR is almost certainly preferred, since it did at least as well on every count as the CT. Furthermore, the Fed published the FR from July 1979 on, whereas the CT did not become available until 1983.

\section{REFERENCES}

Bernanke, Ben S.; Laubach, Thomas; Mishkin, Frederic S. and Posen, Adam S. Inflation Targeting: Lessons from the International Experience. Princeton: Princeton University Press, 1998.

Diebold, Francis X. and Mariano, Roberto S. "Comparing Predictive Accuracy." Journal of Business and Economic Statistics, July 1995, 13(3), pp. 253-65.

Faust, Jon; Rogers, John H. and Wright, Jonathan H. "News and Noise in G-7 GDP Announcements." International Finance Discussion Papers, Board of Governors of the Federal Reserve System, No. 690, December 2000.

Gavin, William T. and Mandal, Rachel J. "Evaluating FOMC Forecasts." Working Paper 2001-005C, Federal Reserve Bank of St. Louis, August 2002 (forthcoming in International Journal of Forecasting). 
Hansen, Lars Peter. "Large Sample Properties of Generalized Method of Moments Estimators.” Econometrica, July 1982, 50(4), pp. 1029-54.

Holden, Kenneth and Peel, David A. "On Testing for Unbiasedness and Efficiency of Forecasts." Manchester School of Economics and Social Studies, June 1990, 58(2), pp. 120-27.

\section{Appendix}

The FOMC forecasts are taken directly from the monetary policy reports to Congress. The first report was made in February 1979, but forecasts were not included with the initial release of the report.

Tables A1 through A4 include the nominal GDP growth, real GDP growth, inflation, and fourthquarter average unemployment rate forecasts. These forecasts come from the semiannual monetary policy reports made by the Fed. The inflation forecasts in Table A3 include forecasts for a mix of price indices, the output deflator, the CPI, and the chain price index for PCE.

Tables A5 and A6 include the real-time data from the Federal Reserve Bank of Philadelphia web site. The data are constructed from the quarterly data files that include vintages of data that were available in the middle of each indicated monthFebruary, May, August, and November. For example, the February 1980 file contains the data that were available to the FOMC in 1980, when the Fed made its February 1980 monetary policy report. The exception was for 1995. In early 1996, the Bureau of Economic Analysis switched to the chain weighted indices for GDP and delayed publishing the initial release until March of 1996. Therefore, the February data for the fourth-quarter-overfourth-quarter value for 1995 comes from the March issue of the Survey of Current Business (Table 7.1).

Table A7 includes the fourth-quarter-overfourth-quarter growth rates of the monetary aggregates as they were reported following the annual benchmarking in February each year. This is the real-time monetary data that the FOMC would have had at the first FOMC meeting each year. This table also includes the real-time CPI data and PCE chain price data. The monetary growth rates and CPI are taken from the monetary policy reports. The real-time price data for PCE are from the February release of the Survey of Current Business. Table A8 includes the January and June monthly average interest rates for overnight federal funds, 1-year Treasury bills, and 10-year Treasury bonds. These are from the Fed's H.15 release. 


\section{Table A1}

FOMC Nominal GNP/GDP Forecasts by Forecast Horizon

\begin{tabular}{|c|c|c|c|c|c|c|}
\hline & \multicolumn{2}{|c|}{ 6-month } & \multicolumn{2}{|c|}{ 12-month } & \multicolumn{2}{|c|}{ 18-month } \\
\hline & $\mathrm{FR}$ & $\mathrm{CT}$ & $\mathrm{FR}$ & $\mathrm{CT}$ & $\mathrm{FR}$ & $\mathrm{CT}$ \\
\hline 1979 & 8 to 10 & & & & & \\
\hline 1980 & 5 to 7.5 & & 7.5 to 11 & & 8.5 to 11.5 & \\
\hline 1981 & 10 to 11.5 & & 9 to 12 & & 8.5 to 11.5 & \\
\hline 1982 & 5.5 to 7.5 & & 8 to 10.5 & & 9.5 to 12.25 & \\
\hline 1983 & 9.25 to 10.75 & 9.75 to 10 & 7.25 to 11.25 & 8 to 9 & 7 to 9.5 & \\
\hline 1984 & 9.5 to 11.5 & 10.5 to 11 & 8 to 10.5 & 9 to 10 & 7 to 10.25 & 9 to 10 \\
\hline 1985 & 6.25 to 7.75 & 6.5 to 7 & 7 to 8.5 & 8.5 to 8 & 6.75 to 9.5 & 8 to 9 \\
\hline 1986 & 3.75 to 6.5 & 4.75 to 5.75 & 5 to 8.5 & 6.5 to 7.25 & 5.5 to 8.5 & 7 to 7.5 \\
\hline 1987 & 5.75 to 7.25 & 6.25 to 7 & 4.5 to 7.5 & 5.75 to 6.5 & 5 to 8.25 & 6 to 7.5 \\
\hline 1988 & 4 to 7 & 5.75 to 6.75 & 4 to 6.5 & 5.25 to 6 & 5 to 8 & 5.75 to 7 \\
\hline 1989 & 5 to 7.75 & 6 to 7 & 5.5 to 8.5 & 6.5 to 7.5 & 4 to 7.5 & 5 to 7 \\
\hline 1990 & 5 to 6.5 & 5.5 to 6.5 & 4 to 7 & 5.5 to 6.5 & 4.25 to 7.5 & 5.5 to 6.75 \\
\hline 1991 & 3.75 to 5.75 & 4.5 to 5.25 & 3.5 to 5.5 & 3.75 to 5.25 & 3.5 to 7 & 5.25 to 6.5 \\
\hline 1992 & 5 to 6.25 & 5.25 to 6 & 4.5 to 5.75 & 5 to 6.25 & 4 to 6.75 & 5.5 to 6.5 \\
\hline 1993 & 4.75 to 6.25 & 5 to 5.75 & 5.25 to 6.25 & 5.5 to 6 & 4.5 to 7 & 5.5 to 6.25 \\
\hline 1994 & 5.25 to 6.5 & 5.5 to 6 & 4.75 to 7.5 & 5.5 to 6 & 4.5 to 6.75 & 5 to 6.5 \\
\hline 1995 & 3.75 to 5.25 & 4.25 to 4.75 & 4.75 to 6.5 & 5 to 6 & 4.5 to 6.25 & 5 to 5.5 \\
\hline 1996 & 4.75 to 5.75 & 5 to 5.5 & 4 to 5 & 4.25 to 4.75 & 4.625 to 5.5 & 4.75 to 5.375 \\
\hline 1997 & 5 to 6 & 5 to 5.5 & 4.25 to 5.25 & 4.5 to 4.75 & 4 to 5.5 & 4.25 to 5 \\
\hline 1998 & 4.25 to 5 & 4.5 to 5 & 3.5 to 5 & 3.75 to 4.5 & 4.25 to 5.75 & 4.5 to 5 \\
\hline 1999 & 4.75 to 5.5 & 5 to 5.5 & 3.75 to 5 & 4 to 4.5 & 4 to 5.5 & 4.25 to 5 \\
\hline 2000 & 6 to 7.25 & 6.25 to 6.75 & 5 to 6 & 5.25 to 5.5 & 4 to 5.25 & 4 to 5 \\
\hline 2001 & 3.25 to 5 & 3.5 to 4.25 & 3.75 to 5.25 & 4 to 5 & 5 to 6.25 & 5.5 to 6 \\
\hline
\end{tabular}

NOTE: The date refers to the calendar year being forecast. For example, the 18-month FR forecast for 1980 (8.5 to 11.5$)$ was made in July 1979. 


\section{Table A2}

FOMC Real GNP/GDP Forecasts by Forecast Horizon

\begin{tabular}{|c|c|c|c|c|c|c|}
\hline & \multicolumn{2}{|c|}{ 6-month } & \multicolumn{2}{|c|}{ 12-month } & \multicolumn{2}{|c|}{ 18-month } \\
\hline & $F R$ & $\mathrm{CT}$ & $\mathrm{FR}$ & $\mathrm{CT}$ & $\mathrm{FR}$ & $\mathrm{CT}$ \\
\hline 1979 & -2 to -0.5 & & & & & \\
\hline 1980 & -5 to -2.5 & & -2.5 to 0.5 & & -0.5 to 2 & \\
\hline 1981 & 1 to 3.5 & & -1.5 to 1.5 & & 0.5 to 3 & \\
\hline 1982 & 0.5 to 1.5 & & 0.5 to 3 & & 1 to 4 & \\
\hline 1983 & 4.75 to 6 & 5 to 5.75 & 3 to 5.5 & 3.5 to 4.5 & 2.5 to 4 & \\
\hline 1984 & 6 to 7 & 6.25 to 6.75 & 3.5 to 5 & 4 to 4.75 & 3 to 5 & 4 to 4.5 \\
\hline 1985 & 2.25 to 3.25 & 2.75 to 3 & 3.25 to 4.25 & 3.5 to 4 & 2 to 4 & 3 to 3.25 \\
\hline 1986 & 2.25 to 3.5 & 2.5 to 3 & 2.75 to 4.25 & 3 to 3.5 & 2 to 4 & 2.5 to 3.25 \\
\hline 1987 & 2 to 3.75 & 2.5 to 3 & 2 to 4 & 2.5 to 3 & 2 to 4.25 & 3 to 3.5 \\
\hline 1988 & 1 to 3.25 & 2.75 to 3 & 0.5 to 3 & 2 to 2.5 & 1 to 3 & 2.5 to 3 \\
\hline 1989 & 1.5 to 2.75 & 2 to 2.5 & 1.5 to 3.25 & 2.5 to 3 & 1 to 3 & 2 to 2.5 \\
\hline 1990 & 1 to 2 & 1.5 to 2 & 1 to 2.25 & 1.75 to 2 & 1 to 2.5 & 1.5 to 2 \\
\hline 1991 & 0.5 to 1.5 & 0.75 to 1 & -0.5 to 1.5 & 0.75 to 1.5 & 0 to 3 & 1.75 to 2.5 \\
\hline 1992 & 2 to 3.25 & 2.25 to 2.75 & 1.5 to 2.75 & 1.75 to 2.5 & 2 to 3.5 & 2.25 to 3 \\
\hline 1993 & 2 to 3.5 & 2.25 to 2.75 & 2.5 to 4 & 3 to 3.25 & 2.5 to 3.5 & 2.75 to 3 \\
\hline 1994 & 3 to 3.5 & 3 to 3.25 & 2.5 to 3.75 & 3 to 3.25 & 2 to 3.25 & 2.5 to 3.25 \\
\hline 1995 & 1.375 to 3 & 1.5 to 2 & 2 to 3.25 & 2 to 3 & 2.25 to 2.75 & 2.5 to 2.75 \\
\hline 1996 & 2.5 to 3 & 2.5 to 2.75 & 1.5 to 2.5 & 2 to 2.25 & 2.125 to 3 & 2.25 to 2.75 \\
\hline 1997 & 3 to 3.5 & 3 to 3.25 & 2 to 2.5 & 2 to 2.25 & 1.5 to 2.5 & 1.75 to 2.25 \\
\hline 1998 & 2.75 to 3.25 & 3 to 3.25 & 1.75 to 3 & 2 to 2.75 & 2 to 3 & 2 to 2.5 \\
\hline 1999 & 3.25 to 4 & 3.5 to 3.75 & 2 to 3.5 & 2.5 to 3 & 2 to 3 & 2 to 2.5 \\
\hline 2000 & 3.75 to 5 & 4 to 4.5 & 3.25 to 4.25 & 3.5 to 3.75 & 2 to 3.5 & 2.5 to 3 \\
\hline 2001 & 1 to 2 & 1.25 to 2 & 2 to 2.75 & 2 to 2.5 & 2.5 to 4 & 3.25 to 3.75 \\
\hline
\end{tabular}




\section{Table A3}

FOMC Inflation Forecasts by Forecast Horizon

\begin{tabular}{|c|c|c|c|c|c|c|}
\hline & \multicolumn{2}{|c|}{ 6-month } & \multicolumn{2}{|c|}{ 12-month } & \multicolumn{2}{|c|}{ 18-month } \\
\hline & $\mathrm{FR}$ & $\mathrm{CT}$ & FR & $\mathrm{CT}$ & $F R$ & $\mathrm{CT}$ \\
\hline 1979 & 9.5 to 11 & & & & & \\
\hline 1980 & 9 to 10 & & 9 to 11 & & 8.5 to 10.5 & \\
\hline 1981 & 7.5 to 9 & & 9 to 10.5 & & 7.75 to 9.5 & \\
\hline 1982 & 4.75 to 6 & & 6.5 to 7.75 & & 6.5 to 8.5 & \\
\hline 1983 & 4 to 5.25 & 4.25 to 4.75 & 3.5 to 5.5 & 4 to 5 & 4 to 5.75 & \\
\hline 1984 & 3.25 to 4.5 & 4 to 4.5 & 4 to 6 & 4.5 to 5 & 3.25 to 6.5 & 4.25 to 5 \\
\hline 1985 & 3.5 to 4.25 & 3.75 to 4 & 3 to 4.75 & 3.5 to 4 & 3.5 to 6.5 & 5.25 to 5.5 \\
\hline 1986 & 1.5 to 3.25 & 2.25 to 2.75 & 2.5 to 4.5 & 3 to 4 & 3 to 5.5 & 3.75 to 4.75 \\
\hline 1987 & 3 to 4.25 & 3.5 to 4 & 2.5 to 4 & 3 to 3.5 & 1.5 to 4.25 & 3 to 4 \\
\hline 1988 & 2.75 to 4 & 3 to 3.75 & 2.5 to 4 & 3.25 to 3.75 & 2.5 to 5 & 3.75 to 4.25 \\
\hline 1989 & 4.5 to 5.75 & 5 to 5.5 & 3.5 to 5.5 & 4.5 to 5 & 2 to 5 & 3 to 4.5 \\
\hline 1990 & 4 to 5 & 4.5 to 5 & 3.5 to 5 & 4 to 4.5 & 3 to 5.75 & 4.5 to 5 \\
\hline 1991 & 3 to 4.5 & 3.25 to 3.75 & 3 to 4.5 & 3.25 to 4 & 3.5 to 5 & 3.75 to 4.5 \\
\hline 1992 & 3 to 3.5 & 3 to 3.5 & 2.5 to 3.5 & 3 to 3.5 & 2.5 to 4.25 & 3 to 4 \\
\hline 1993 & 3 to 3.5 & 3 to 3.25 & 2.5 to 3 & 2.5 to 2.75 & 2.5 to 4 & 2.75 to 3.25 \\
\hline 1994 & 2.5 to 3.5 & 2.75 to 3 & 2.25 to 4 & 3 to 3 & 2 to 4.25 & 3 to 3.5 \\
\hline 1995 & 3 to 3.5 & 3.125 to 3.375 & 2.75 to 3.75 & 3 to 3.5 & 2 to 4.5 & 2.75 to 3.5 \\
\hline 1996 & 3 to 3.25 & 3 to 3.25 & 2.5 to 3 & 2.75 to 3 & 2.5 to 3.5 & 2.875 to 3.25 \\
\hline 1997 & 2 to 2.75 & 2.25 to 2.5 & 2.75 to 3.5 & 2.75 to 3 & 2.5 to 3.25 & 2.75 to 3 \\
\hline 1998 & 1.25 to 2.25 & 1.75 to 2 & 1.5 to 2.5 & 1.75 to 2.25 & 2.5 to 3 & 2.5 to 3 \\
\hline 1999 & 1.75 to 2.5 & 2.25 to 2.5 & 1.5 to 2.5 & 2 to 2.5 & 1.5 to 3 & 2 to 2.5 \\
\hline 2000 & 2 to 2.75 & 2.5 to 2.75 & 1.5 to 2.5 & 1.75 to 2 & 1.75 to 2.5 & 2.25 to 2.5 \\
\hline 2001 & 2 to 2.75 & 2 to 2.5 & 1.75 to 2.5 & 1.75 to 2.25 & 1.75 to 3 & 2 to 2.5 \\
\hline
\end{tabular}

NOTE: From 1979 through 1988, the FOMC reported forecasts for the GNP/GDP deflator; from 1989 through 1999, the FOMC reported forecasts for the CPI; and in 2000 and 2001, the FOMC reported forecasts for the chain price index for PCE. See, also, note for Table A1. 


\section{Table A4}

FOMC Fourth-Quarter Average Unemployment Rate Forecasts

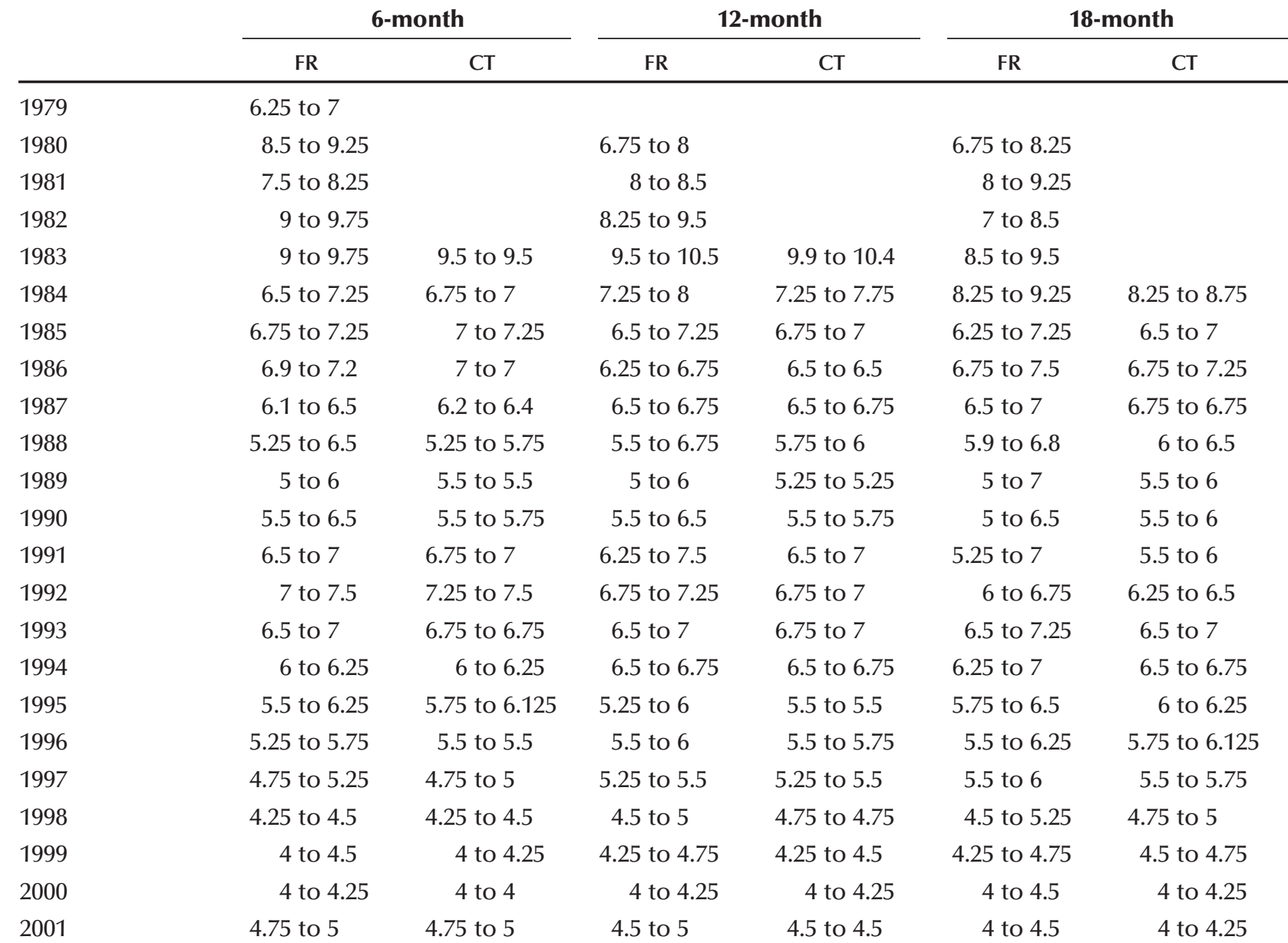

NOTE: See note for Table A1. 


\section{Table A5}

Real-Time Data Available in February and May

\begin{tabular}{|c|c|c|c|c|c|c|c|c|}
\hline & \multicolumn{4}{|c|}{ February } & \multicolumn{4}{|c|}{ May } \\
\hline & $\begin{array}{c}\text { Nominal } \\
\text { output } \\
\text { growth }\end{array}$ & $\begin{array}{c}\text { Real } \\
\text { output } \\
\text { growth }\end{array}$ & Inflation & $\begin{array}{l}\text { Unemployment } \\
\text { rate }\end{array}$ & $\begin{array}{c}\text { Nominal } \\
\text { output } \\
\text { growth }\end{array}$ & $\begin{array}{c}\text { Real } \\
\text { output } \\
\text { growth }\end{array}$ & Inflation & $\begin{array}{l}\text { Unemployment } \\
\text { rate }\end{array}$ \\
\hline 1978 & 12.91 & 4.26 & 8.29 & 5.83 & 13.11 & 4.44 & 8.30 & 5.83 \\
\hline 1979 & 9.87 & 0.83 & 8.97 & 5.87 & 9.92 & 0.96 & 8.87 & 5.87 \\
\hline 1980 & 9.82 & -0.03 & 9.86 & 7.50 & 9.39 & -0.34 & 9.75 & 7.50 \\
\hline 1981 & 9.31 & 0.67 & 8.58 & 8.37 & 9.80 & 0.86 & 8.87 & 8.37 \\
\hline 1982 & 3.27 & -1.23 & 4.56 & 10.67 & 3.50 & -0.87 & 4.40 & 10.67 \\
\hline 1983 & 10.37 & 6.06 & 4.06 & 8.47 & 10.50 & 6.20 & 4.05 & 8.47 \\
\hline 1984 & 9.35 & 5.62 & 3.53 & 7.20 & 9.53 & 5.70 & 3.62 & 7.20 \\
\hline 1985 & 5.78 & 2.54 & 3.15 & 7.00 & 5.37 & 2.14 & 3.16 & 7.00 \\
\hline 1986 & 4.42 & 2.21 & 2.16 & 6.83 & 4.18 & 2.04 & 2.10 & 6.83 \\
\hline 1987 & 7.23 & 3.85 & 3.25 & 5.90 & 7.45 & 4.00 & 3.31 & 5.90 \\
\hline 1988 & 7.02 & 2.71 & 4.19 & 5.33 & 7.23 & 2.81 & 4.29 & 5.33 \\
\hline 1989 & 6.37 & 2.43 & 3.85 & 5.30 & 6.44 & 2.57 & 3.77 & 5.30 \\
\hline 1990 & 4.34 & 0.35 & 3.98 & 5.90 & 4.50 & 0.49 & 3.99 & 5.90 \\
\hline 1991 & 3.22 & 0.23 & 2.99 & 6.97 & 3.28 & 0.27 & 3.00 & 6.97 \\
\hline 1992 & 5.36 & 2.92 & 2.37 & 7.33 & 5.71 & 3.15 & 2.48 & 7.33 \\
\hline 1993 & 5.11 & 2.84 & 2.21 & 6.53 & 5.36 & 3.10 & 2.19 & 6.53 \\
\hline 1994 & 6.38 & 4.00 & 2.28 & 5.57 & 6.47 & 4.14 & 2.24 & 5.57 \\
\hline 1995 & $3.68^{*}$ & $1.27^{*}$ & $2.37^{*}$ & 5.57 & 3.68 & 1.27 & 2.37 & 5.57 \\
\hline 1996 & 5.18 & 3.36 & 1.76 & 5.27 & 4.97 & 3.14 & 1.77 & 5.27 \\
\hline 1997 & 5.76 & 3.89 & 1.80 & 4.70 & 5.58 & 3.74 & 1.77 & 4.70 \\
\hline 1998 & 5.07 & 4.15 & 0.88 & 4.40 & 5.17 & 4.25 & 0.88 & 4.40 \\
\hline 1999 & 5.92 & 4.25 & 1.60 & 4.10 & 6.26 & 4.60 & 1.59 & 4.10 \\
\hline 2000 & 5.92 & 3.49 & 2.34 & 3.97 & 5.80 & 3.41 & 2.31 & 3.97 \\
\hline 2001 & 1.94 & 0.13 & 1.81 & 5.60 & 2.34 & 0.48 & 1.86 & 5.60 \\
\hline
\end{tabular}

NOTE: Fourth-quarter-over-fourth-quarter growth rates.

*February real-time values for 1995 were not actually released until March. The values here are taken from the Survey of Current Business, March 1996, Table 7.1. 


\section{Table A6}

\section{Real-Time Data Available in August and November}

\begin{tabular}{|c|c|c|c|c|c|c|c|c|}
\hline & & & gust & & & & mber & \\
\hline & $\begin{array}{c}\text { Nominal } \\
\text { output } \\
\text { growth }\end{array}$ & $\begin{array}{c}\text { Real } \\
\text { output } \\
\text { growth }\end{array}$ & Inflation & $\begin{array}{l}\text { Unemployment } \\
\text { rate }\end{array}$ & $\begin{array}{c}\text { Nominal } \\
\text { output } \\
\text { growth }\end{array}$ & $\begin{array}{c}\text { Real } \\
\text { output } \\
\text { growth }\end{array}$ & Inflation & $\begin{array}{l}\text { Unemployment } \\
\text { rate }\end{array}$ \\
\hline 1978 & 13.39 & 4.80 & 8.20 & 5.83 & 13.39 & 4.80 & 8.20 & 5.83 \\
\hline 1979 & 9.92 & 0.96 & 8.87 & 5.87 & 9.92 & 0.96 & 8.87 & 5.87 \\
\hline 1980 & 9.39 & -0.34 & 9.75 & 7.50 & 9.39 & -0.34 & 9.75 & 7.50 \\
\hline 1981 & 9.63 & 0.72 & 8.84 & 8.37 & 9.63 & 0.72 & 8.84 & 8.37 \\
\hline 1982 & 2.55 & -1.74 & 4.37 & 10.67 & 2.55 & -1.74 & 4.37 & 10.67 \\
\hline 1983 & 10.36 & 6.35 & 3.77 & 8.47 & 10.36 & 6.35 & 3.77 & 8.47 \\
\hline 1984 & 9.53 & 5.70 & 3.62 & 7.20 & 9.53 & 5.70 & 3.62 & 7.20 \\
\hline 1985 & 6.30 & 2.89 & 3.31 & 7.00 & 6.30 & 2.89 & 3.31 & 7.00 \\
\hline 1986 & 4.48 & 2.21 & 2.22 & 6.83 & 4.48 & 2.21 & 2.22 & 6.83 \\
\hline 1987 & 8.32 & 5.04 & 3.12 & 5.90 & 8.32 & 5.04 & 3.12 & 5.90 \\
\hline 1988 & 7.53 & 3.40 & 4.00 & 5.33 & 7.53 & 3.40 & 4.00 & 5.33 \\
\hline 1989 & 5.58 & 1.82 & 3.69 & 5.30 & 5.58 & 1.82 & 3.69 & 5.30 \\
\hline 1990 & 4.50 & 0.49 & 3.99 & 5.90 & 4.50 & 0.49 & 3.99 & 5.90 \\
\hline 1991 & 3.45 & 0.10 & 3.35 & 6.97 & 3.45 & 0.10 & 3.35 & 6.97 \\
\hline 1992 & 5.71 & 3.15 & 2.48 & 7.33 & 6.73 & 3.87 & 2.76 & 7.33 \\
\hline 1993 & 5.01 & 3.11 & 1.84 & 6.53 & 5.01 & 3.11 & 1.84 & 6.53 \\
\hline 1994 & 6.47 & 4.14 & 2.24 & 5.57 & 6.47 & 4.14 & 2.24 & 5.57 \\
\hline 1995 & 3.78 & 1.30 & 2.45 & 5.57 & 3.78 & 1.30 & 2.45 & 5.57 \\
\hline 1996 & 5.57 & 3.25 & 2.24 & 5.27 & 5.57 & 3.25 & 2.24 & 5.27 \\
\hline 1997 & 5.58 & 3.83 & 1.69 & 4.70 & 5.58 & 3.83 & 1.69 & 4.70 \\
\hline 1998 & 5.17 & 4.25 & 0.88 & 4.40 & 5.85 & 4.61 & 1.18 & 4.40 \\
\hline 1999 & 6.52 & 4.96 & 1.48 & 4.10 & 6.52 & 4.96 & 1.48 & 4.10 \\
\hline 2000 & 5.31 & 2.81 & 2.43 & 3.97 & 5.31 & 2.81 & 2.43 & 3.97 \\
\hline 2001 & 2.00 & 0.05 & 1.95 & 5.60 & & & & \\
\hline
\end{tabular}




\section{Table A7}

Real-Time Data for Monetary Aggregates and Other Price Indices

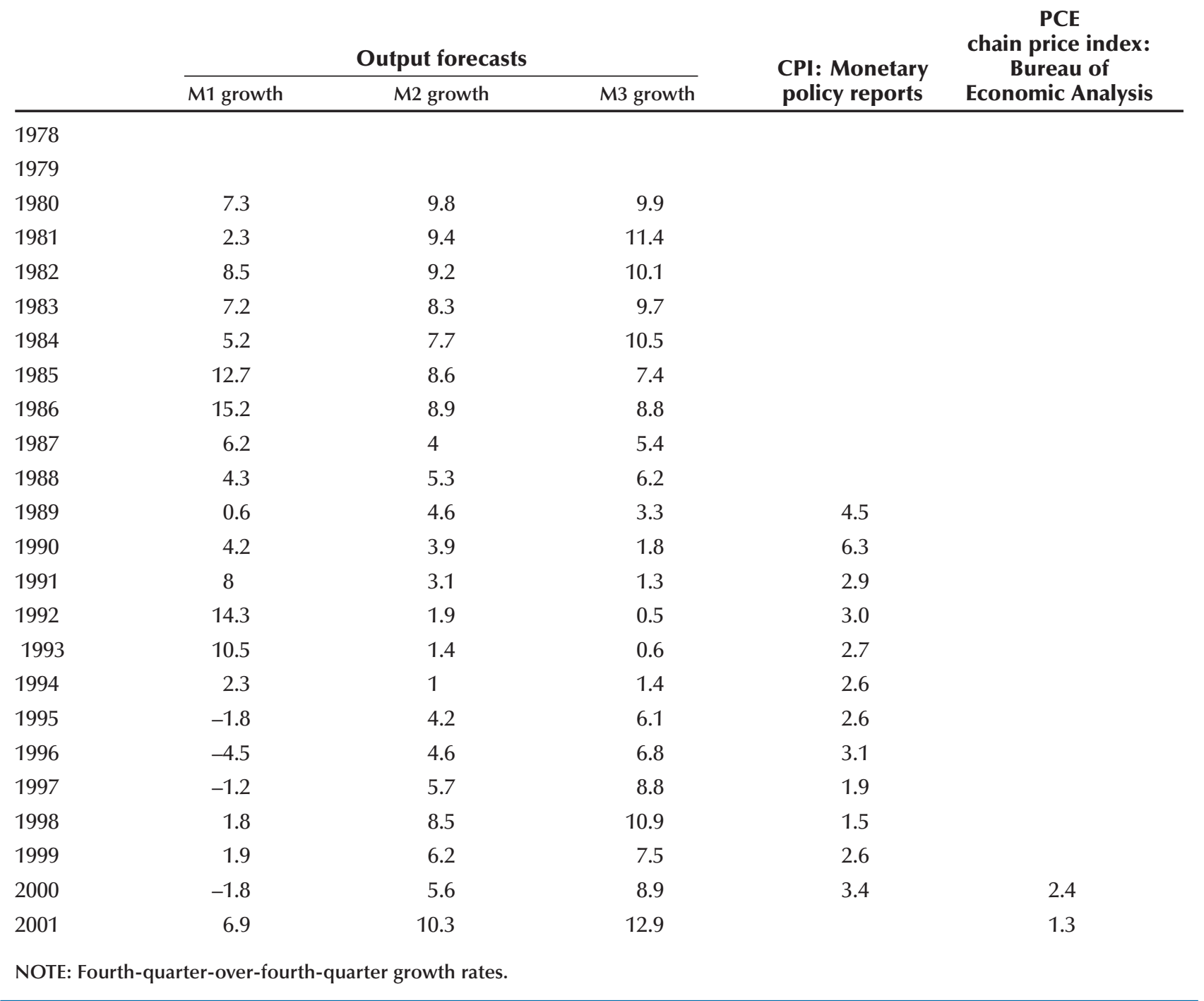




\section{Table A8}

\section{H.15 Interest Rate Data}

January average

\begin{tabular}{|c|c|c|c|c|c|}
\hline & \\
\hline $\begin{array}{l}\text { 10-year } \\
\text { Treasury bond }\end{array}$ & $\begin{array}{c}\text { 1-year } \\
\text { Treasury bill }\end{array}$ & $\begin{array}{c}\text { Overnight } \\
\text { federal funds rate }\end{array}$ & $\begin{array}{l}\text { 10-year } \\
\text { Treasury bond }\end{array}$ & $\begin{array}{c}1 \text { 1-year } \\
\text { Treasury bill }\end{array}$ & $\begin{array}{c}\text { Overnight } \\
\text { federal funds rate }\end{array}$ \\
\hline 7.96 & 7.28 & 6.70 & 8.46 & 8.09 & 7.60 \\
\hline 9.10 & 10.41 & 10.07 & 8.91 & 9.57 & 10.29 \\
\hline 10.80 & 12.06 & 13.82 & 9.78 & 8.16 & 9.47 \\
\hline 12.57 & 14.08 & 19.08 & 13.47 & 14.86 & 19.10 \\
\hline 14.59 & 14.32 & 13.22 & 14.30 & 14.07 & 14.15 \\
\hline 10.46 & 8.62 & 8.68 & 10.85 & 9.66 & 8.98 \\
\hline 11.67 & 9.90 & 9.56 & 13.56 & 12.08 & 11.06 \\
\hline 11.38 & 9.02 & 8.35 & 10.16 & 7.80 & 7.53 \\
\hline 9.19 & 7.73 & 8.14 & 7.80 & 6.73 & 6.92 \\
\hline 7.08 & 5.78 & 6.43 & 8.40 & 6.80 & 6.73 \\
\hline 8.67 & 6.99 & 6.83 & 8.92 & 7.49 & 7.51 \\
\hline 9.10 & 9.05 & 9.12 & 8.28 & 8.44 & 9.53 \\
\hline 8.21 & 7.92 & 8.23 & 8.48 & 8.10 & 8.29 \\
\hline 8.09 & 6.64 & 6.91 & 8.28 & 6.36 & 5.90 \\
\hline 7.03 & 4.15 & 4.03 & 7.26 & 4.17 & 3.76 \\
\hline 6.60 & 3.50 & 3.02 & 5.96 & 3.54 & 3.04 \\
\hline 5.75 & 3.54 & 3.05 & 7.10 & 5.27 & 4.25 \\
\hline 7.78 & 7.05 & 5.53 & 6.17 & 5.64 & 6.00 \\
\hline 5.65 & 5.09 & 5.56 & 6.91 & 5.81 & 5.27 \\
\hline 6.58 & 5.61 & 5.25 & 6.49 & 5.69 & 5.56 \\
\hline 5.54 & 5.24 & 5.56 & 5.50 & 5.41 & 5.56 \\
\hline 4.72 & 4.51 & 4.63 & 5.90 & 5.10 & 4.76 \\
\hline 6.66 & 6.12 & 5.46 & 6.10 & 6.17 & 6.53 \\
\hline 5.16 & 4.81 & 5.98 & 5.28 & 3.58 & 3.97 \\
\hline
\end{tabular}

